\title{
O PROJETO POLÍTICO-PEDAGÓGICO COMO INSTRUMENTO DE GESTÃO DEMOCRÁTICA E PARTICIPATIVA
}

\author{
http://dx.doi.org/10.5902/2318133830480
}

\author{
Viviane da Costa Bastos \\ Bárbara de Britto Terra Nova Gonçalves \\ Ana Cristina Vieira Alves \\ Fundação Técnico-Educacional Souza Marques, Brasil.
}

\begin{abstract}
Resumo
A concretização de uma prática de gestão democrática e participativa no cotidiano das escolas enfrenta muitos desafios, tais como a ruptura com a cultura autoritária que rejeita os questionamentos nas imposições de ordem e poder. No entanto, para a elaboração de um sistema educacional democrático e participativo, torna-se relevante implantar um espaço aberto para discussões no interior dos espaços escolares. O gestor educacional pode possibilitar a intervenção de práticas educativas, tendo em vista a realidade da comunidade escolar. Assim, esse artigo busca discutir como a elaboração do projeto político-pedagógico - PPP - pode se tornar um instrumento de gestão democrática e participativa. Os resultados obtidos apresentam a relevância da promoção de um contexto institucional que contribua para a formação de cidadãos construtores e transformadores da sociedade.
\end{abstract}

Palavras-chave: projeto político-pedagógico; gestão democrática e participativa; escola.

\section{THE POLITICAL-PEDAGOGICAL PROJECT AS AN INSTRUMENT OF DEMOCRATIC AND PARTICIPATORY MANAGEMENT}

Abstract

The implementation of a democratic and participatory practice management in the routine of schools has faced many challenges, such as a break with the authoritarian culture that rejects the questionings in the impositions of order and power. However, for the construction of a democratic and participatory educational system, it is important to establish an open space for discussions within the school spaces. The educational manager may allow the intervention of educational practices, in view of the reality of the school community. Thus, this article seeks to discuss how the construction of the political-pedagogical project - PPP - can become an instrument of democratic and participative management, based on authors who approach on democratic management in the legal, political and educational scenario. The results show the relevance of promoting an institutional context that contributes to the formation of builders and transformers citizens of society.

Key-words: political-pedagogical project; democratic and participatory management; school. 


\section{Introdução}

N o final da década de 1980, período marcado pela redemocratização do nosso país, a gestão democrática e participativa tornou-se um dos centros de debate no cenário político e educacional.

Esse período histórico, que representou o fim de um regime militar de duas décadas, foi marcado por um sentimento de esperança por um Brasil mais justo e equânime, que buscava uma educação de qualidade para o povo brasileiro. Porém, a educação não foi priorizada no desenvolver da história. Nesse contexto, podemos perceber o sucateamento da escola pública e a desvalorização dos profissionais de ensino.

A partir da Constituição Federal de 1988, a gestão democrática foi reconhecida como um dos temas fundamentais e determinantes para a melhoria no desempenho escolar e na qualidade de ensino. Assim, torna-se relevante refletirmos a respeito da atuação dos gestores educacionais, por serem profissionais que podem articular práticas coletivas como o planejamento institucional expressas no projeto político-pedagógico PPP.

Veiga (2003) aborda o PPP como um instrumento que pode organizar "o trabalho pedagógico na escola como um todo" (p. 11), direcionando caminhos e reunindo ideias, fundamentos, orientações curriculares e organizacionais no interior dos espaços educacionais.

De acordo com a Lei de Diretrizes e Bases da Educação (LDB 9.394/96), o PPP é um instrumento que norteia o trabalho pedagógico da instituição escolar e atribui ao professor a tarefa de participar da elaboração e cumprimento do plano de trabalho, segundo a proposta pedagógica do estabelecimento de ensino (Brasil, 1996). Desta forma, a escola constitui-se como um espaço que pode provocar discussões, possibilitando a troca e a reflexão sobre as ações vivenciadas nas práticas cotidianas e nas inter-relações, contribuindo para reunir informações que sejam significativas no desenvolvimento do trabalho pedagógico e administrativo da instituição.

\section{O projeto político-pedagógico como instrumento de trabalho}

Nos dias atuais, estudos abarcam o projeto político-pedagógico como um instrumento relevante para o desenvolvimento do trabalho pedagógico e a melhoria da qualidade de ensino, por envolver projetos organizados pelas instituições escolares, estruturados a partir de diferentes dimensões e tendo como base a realidade do corpo discente.

Segundo o sentido etimológico da palavra projeto, o termo origina-se do latim projectic, que significa lançar a diante. Almeida (2002) aborda que o projeto constitui-se uma atividade humana, inseparável do sentido da ação, pois ao construir projetos, planejamos o que temos a intenção de realizar e tornar real.

Para Machado (2000), o "projeto" não se constitui "uma simples representação do futuro, do amanhã, do possível, de uma ideia; é o futuro a fazer, um amanhã a concretizar, um possível a transformar em real, uma ideia a se transformar em acto" (p. 6). Nesse sentido, o ato de projetar requer flexibilidade, avaliação e visão crítica para a realização de ações que possibilitem a aprendizagem dos alunos. 
Segundo Gadotti (1994), "todo projeto supõe rupturas com o presente e promessas para o futuro projetar atores e autores" (p. 579). Desta forma, nota-se que o PPP não se encontra apenas agregado a planos de ensino e diversas atividades. Não é um plano constituído, arquivado e encaminhado às autoridades educacionais para comprovação do cumprimento de normas e regras burocráticas. Esse instrumento implica colocar em prática as decisões tomadas por todos os envolvidos no processo educacional.

Por se tratar de uma articulação de cunho social, político e educacional que visa envolver interesses reais e coletivos da comunidade, o PPP constitui-se como político, por comprometer-se com a formação do cidadão. Para Saviani (1983), "a dimensão política se cumpre na medida em que ela se realiza enquanto prática especificamente pedagógica" (p. 93).

Saviani (1983) corrobora que o projeto organiza a divisão do trabalho pedagógico em dois níveis: a organização da escola como um todo e a organização de sala de aula. Desta forma, diminui a fragmentação que reforça as diferenças e hierarquizam os poderes de decisão fazendo com que todos se envolvam na prática pedagógica.

A escola pode construir sua autonomia e identidade, significando-se como um espaço público, de debate, diálogo e com visões coletivas. Neste âmbito, a busca por uma nova organização da escola pode se tornar um desafio para os gestores, educadores, pais e alunos. Freitas (2004) ressalta que o PPP constitui-se como um instrumento de gestão e compromisso pedagógico coletivo:

O projeto pedagógico não é uma peça burocrática e sim um instrumento de gestão e de compromissso político e pedagógico coletivo. Não é feito para ser mandado para alguém ou algum setor, mas sim para ser usado como referência para as lutas da escola. É um resumo das condições e funcionamento da escola e ao mesmo tempo um diagnóstico seguido de compromisso aceitos e firmados pela escola consigo mesma. (p. 69)

O desenvolvimento do PPP pode contribuir para que se alcancem os objetivos escolares e promova o comprometimento da instituição com seus alunos.

\section{A gestão democrática e participativa no contexto escolar}

De acordo com Libâneo (2012), democracia constitui-se um regime político baseado nos princípios da soberania popular e da distribuição equitativa do poder. A Constituição Federal de 1988 incorpora a gestão democrática como um dos princípios que devem nortear o ensino. Gadotti e Libâneo (2012) defendem a instituição de uma gestão escolar participativa como forma de assegurar uma educação de melhor qualidade.

Entretanto, a existência de uma lei, por si só, não é suficiente para garantir a participação de todos na gestão escolar; esta é uma elaboração contínua e coletiva, que requer disponibilidade para promover mudanças e competência da equipe na busca por níveis progressivos de autonomia pedagógica, administrativa e financeira.

Segundo Libâneo (2012, p. 79), a participação é o principal meio de assegurar a gestão democrática da escola, possibilitando o envolvimento de profissionais e usuários no processo de tomada de decisões e no funcionamento da organização escolar. Para o autor, o conceito de participação proporciona um melhor conhecimento dos objetivos e metas, da estrutura organizacional e de sua dinâmica, das relações da escola com a comunidade, e favorece uma aproximação maior entre professores, alunos e pais. 
Assim, a partir do estreitamento de relações e criação de parcerias, a autonomia torna-se um processo de conquista e interação de toda a comunidade escolar, um princípio que se opõe às formas autoritárias de tomada de decisões e possibilita a proximidade entre professores, alunos, pais e comunidade.

Dias (1998) ressalta que a "participação do grupo na tomada de decisões é a garantia de maior identificação de todos com o trabalho a ser realizado" (p. 278). Conforme o autor, para que a gestão democrática se efetive, torna-se relevante 0 comprometimento e a integração de toda a equipe pedagógica, possibilitando compreender o valor de sua participação e propondo ações coletivas que visem à qualidade do ensino.

Para Libâneo (2012), a educação "deve ser entendida como fator de realização da cidadania, com padrões de qualidade da oferta e do produto, na luta contra a superação das desigualdades sociais e da exclusão social" (p. 133). Logo, cabe ao gestor preocuparse em colher sugestões, ideias e contribuições dos educadores, estabelecer reflexões acerca do regimento escolar, do projeto político-pedagógico, bem como estar atento ao seu cumprimento, possuir uma postura ética em relação aos desafios da participação e efetividade da coletividade nas decisões e deliberações pedagógicas e administrativas visando sempre a qualidade do ensino.

A gestão escolar democrática se desenvolve num processo de elaboração e de democratização da educação. Não existem receitas, fórmulas de gestão prontas, elas se estabelecem no processo político, social e cultural em que se insere cada escola. Neste contexto, percebemos que a atuação do gestor nas práticas coletivas de planejamento, na organização do trabalho pedagógico e na avaliação favorece a consolidação de uma escola comprometida com o papel político e social.

Assim, torna-se um desafio compreender os princípios da gestão democrática para que a organização do trabalho escolar aconteça de modo crítico e coerente. Segundo Freire (2016), "de nada adianta o discurso competente se a ação pedagógica é impermeável a mudanças" (p. 12).

\section{Elaboração do PPP a partir do trabalho coletivo}

O projeto político-pedagógico configura-se em uma ferramenta de planejamento e avaliação escolar, eleborado de forma coletiva, em um movimento constante de ação, reflexão e discussão sobre o que ocorre no interior dos espaços escolares. O gestor é o profissional responsável em dinamizar a escola e motivar todos os sujeitos envolvidos nesse processo.

O PPP constitui-se projeto por direcionar e definir ações a partir de um compromisso coletivo; político porque reflete a escolha de caminhos e prioridades na formação do cidadão, como membro ativo e transformador da sociedade em que vive; pedagógico porque expressa as atividades pedagógicas e didáticas que levam a escola a alcançar os seus objetivos educacionais.

É importante que o PPP seja percebido em sua globalidade e reconhecido como um instrumento que identifica a escola como uma instituição social, voltada para a educação. Logo, ao se construir o projeto político-pedagógico, torna-se fundamental compreender a realidade que circunda a escola, expressa no contexto macro da sociedade: econômico, político e social. 
A realidade macro da sociedade afeta a vida da escola, assim como também a afeta a sua realidade interna específica, o seu funcionamento, possibilidades e limites. De acordo com Freitas (2004),

o projeto pedagógico não é uma peça burocrática e sim um instrumento de gestão e de compromisso político e pedagógico coletivo. Não é feito para ser mandado para alguém ou algum setor,mas sim para ser usado como referência para as lutas da escola. É um resumo das condições e funcionamento da escola e ao mesmo tempo um diagnóstico seguido de compromissos aceitos e firmados pela escola consigo mesma - sob o olhar atento do poder público. (p. 69)

O projeto político-pedagógico da escola, quando bem fundamentado e administrado, pode contribuir para que a escola alcance seus objetivos e missões. Desta forma, a gestão do projeto político-pedagógico precisa atentar-se quanto a todos os acontecimentos econômicos e sociais que possam ocorrer no contexto exterior à dimensão escolar.

Segundo Freitas (2004), o enfoque da qualidade abrange uma totalidade de fatores essenciais à vida de uma instituição que se pauta por uma gestão participativa e democrática. O autor aborda que as instituições também aprendem, como as pessoas. Como um coletivo, as instituições têm uma memória das suas lutas e demandas e são um organismo vivo que reflete sobre sua realidade e seu futuro, assumindo postura de não neutralidade diante dos distintos caminhos a seguir.

Para Luckesi (1998), a avaliação fundamenta novas decisões, redimensiona as ações educativas e características necessárias às escolas para que se cumpra 0 propósito e a intencionalidade do planejamento:

A avaliação poderia ser compreendida como uma crítica de percurso de ação, seja ela curta, seja prolongada. Enquanto o planejamento dimensiona o que se vai construir, a avaliação subsidia essa elaboração, porque fundamenta novas decisões. [...] a avaliação como crítica de percurso é uma ferramenta necessária ao ser humano no processo de elaboração dos resultados que planificou produzir, assim como o é no redimensionamento da direção da ação. (Luckesi, 1998, p. 116)

Segundo Freitas (2004), "a peça chave na questão da avaliação institucional é o projeto político-pedagógico da escola e suas relações com a gestão escolar. Tem como pressuposto a gestão escolar democrática e participativa e articula seus compromissos em torno à elaboração do projeto pedagógico da escola" (p. 68). Neste sentido, parte de uma concepção de educação aceita pelo coletivo e que deve unir as ações deste na escola. Inclui não só a comunidade interna da escola, mas envolve relações com a família e com a comunidade externa mais ampla.

Libâneo (2012) enfatiza que a escola é vista como uma organização política, ideológica e cultural em que indivíduos e grupos de diferentes interesses, preferências, crenças, valores e percepções da realidade mobilizam poderes e elaboram processos de negociação, pactos e enfrentamentos.

Assim, é relevante que o projeto político-pedagógico da escola seja construído a partir do trabalho coletivo, contemplando interesses, percepções, tomada de decisões que busquem melhorias e mudanças nas atividades pedagógicas. 


\section{Considerações finais}

Neste texto buscou-se discutir como a elaboração coletiva do projeto políticopedagógico pode se tornar um instrumento de gestão democrática e participativa nos espaços escolares.

Cabe à gestão educacional promover um contexto institucional saudável, no qual as pessoas se sintam responsáveis pela escola, pelos seus fins, em formar cidadãos criativos, construtores e transformadores da sociedade e articular de forma harmônica os fatores materiais e humanos que se encontram em seu interior, ou seja, os recursos que a escola têm para atingir os seus objetivos de ensino e a aprendizagem dos alunos.

Os espaços escolares, visando a um ensino de qualidade, pode lançar mão de métodos e técnicas de administração sem, contudo, descaracterizar a sua essência e especificidade de instrução e formação e sem transformá-la em uma organização empresarial que visa apenas à produtividade. Assim, parte-se da premissa de que a escola forma os alunos para a vida, instrui e forma cidadãos críticos, capazes de decidir caminhos, tornando-se agentes de sua história, mesmo condicionados a quaisquer outras circunstâncias.

No entanto, para que a escola alcance os seus objetivos, é fundamental que a elaboração e o acompanhamento do projeto político-pedagógico estejam alicerçados em uma administração participativa, em que as decisões sejam democratizadas e o seu processo de avaliação e revisão sejam práticas coletivas constantes, oportunizando a reflexão para mudanças de direção e caminhos.

A escola pode promover práticas transformadoras, impulsionadas por uma gestão democrática, eficaz e coerente que alcança os seus objetivos pedagógicos e educacionais de forma significativa. Desta forma, os problemas que venham a surgir nos espaços educacionais podem ser superados por movimentos que favoreçam o diálogo, buscam soluções em coletivo, possibilitam mudanças e constroem uma escola mais participativa e democrática.

\section{Referências}

ALMEIDA, Maria Elizabeth Bianconcini de. Como se trabalha com projetos. Revista TV Escola, Brasília, n. 22, 2002, p. 2-5.

BRASIL. Lei n`9394, de 20 de dezembro de 1996. Lei de Diretrizes e Bases da Educação. Disponível em <http://www.presidencia.gov.br/ccivil 03/Leis/L9394.htm> Acesso em 12 dez. 2017.

DIAS, José Augusto. Gestão da Escola. In: Meneses, Joao Gualberto de Carvalho. Estrutura e funcionamento da educação básica. 2 ed. São Paulo: Pioneira, 1998, p. 270280.

FREIRE, Paulo. Pedagogia da autonomia - saberes necessários à prática educativa. São Paulo:Paz e Terra; 2016. p.11-15.

FREITAS, Luiz Carlos. Dialética da inclusão e da exclusão: por uma qualidade negociada e emancipadora nas escolas. In: Escola Viva: elementos para a elaboração de uma educação de qualidade social. GERALDI, Corinta Maria Grisolia; RIOLFI, Claudia Rosa; GARCIA, Maria de Fátima. Campinas: Mercado de Letras, 2004, p. 65-75.

GADOTTI, Moacir. Projeto político-pedagógico da escola: In: GADOTTI, Moacir; ROMÃO, José Eustáquio. Autonomia da escola: princípios e propostas. São Paulo: Cortez, 2001.

\begin{tabular}{|l|l|l|l|l|l} 
Regae: Rev. Gest. Aval. Educ. & Santa Maria & v. 7 & n. 15 & Maio/ago. 2018 $87-93$
\end{tabular} 
LIBÂNEO, José Carlos. Educação escolar, políticas, estruturas e organização. São Paulo: Cortez, 2012.

LUCKESI, Cipriano Carlos. Avaliação da aprendizagem escolar. São Paulo: Cortez, 1998. MACHADO, José Nilson de. Educação: projetos e valores. São Paulo: Escrituras, 2000.

VEIGA, Ilma Passos Alencastro. Projeto político-pedagógico da escola: uma elaboração possível. Campinas: Papirus, 2003.

VEIGA, IIma Passos Alencastro. Inovações e projeto político-pedagógico: uma relação regulatória ou emancipatória? Cadernos Cedes, Campinas, v. 23, n. 61, p. 267-281.

Viviane da Costa Bastos é mestre em Ensino em Educação Básica pela Universidade do Estado do Rio de Janeiro e professora no curso de Pedagogia na Fundação Técnico-Educacional Souza Marques.

Endereço: Alameda Alberto Flores, 112 - 20755-080 - Rio de Janeiro - RJ - Brasil.

E-mail: professoravivianecb@yahoo.com.br.

Bárbara de Britto Terra Nova Gonçalves é mestre em Ensino em Educação Básica pela Universidade do Estado do Rio de Janeiro, coordenadora do curso de Pedagogia e pós-graduação em Educação Especial e Inclusiva na Fundação Técnico-Educacional Souza Marques.

Endereço: Rua Martins Lage, 419 - 20780-110 - Rio de Janeiro - RJ - Brasil.

E-mail: barbara.goncalves@ftesm.edu.br.

Ana Cristina Vieira Alves é professora das séries iniciais na educação básica e estudante do curso de Pedagogia na Fundação Técnico-Educacional Souza Marques.

Endereço: Av. Capitão Menezes, 1595 - 21320-040 - Rio de Janeiro - RJ - Brasil.

E-mail: anacrispedagogia@gmail.com.

Recebido em 18 de dezembro de 2017.

Aceito em 14 de março de 2018. 